\title{
0 pragmatismo brasileiro na cooperação militar com os Estados Unidos, nas décadas de 1930 e 40
}

EDUARDO MUNHOZ SVARTMAN*

\begin{abstract}
Resumo: Argumenta-se que houve pragmatismo nas negociações militares do Brasil com os Estados Unidos, no período aqui abordado. A associação assimétrica que se desenhava visava, para o Brasil, objetivos ligados ao seu imediato rearmamento e à obtenção de facilidades para uma industrialização nacional capaz de, a longo prazo, suprir suas Forças Armadas. Essa pauta se prolongou nos primeiros anos da Guerra Fria e foi o que definiu a conveniência ou não da cooperação militar com os EUA desde então.

Abstract: Between the mid 1930's and the end of the 1940's the Brazilian negotiations within North-American military were shaped by the pragmatism. For Brazilian military this asymmetrical association was a way to obtain modern war equipment in short time and to reach facilities for a national industrialization which, in long time, would be able to supply the Armed Forces. This agenda still informed the Brazilian military on the beginning of the Cold War and defined the convenience or not of the cooperation with USA.
\end{abstract}

Palavras-chave: Relações Brasil-EUA. Cooperação militar. Política externa.

Key words: Brazil-USA relations. Military cooperation. Foreign policy.

Na história das relações entre Brasil e Estados Unidos, o período que envolveu os antecedentes e a participação desses países na II Guerra Mundial é uma das temáticas mais investigadas, tanto pela historiografia brasileira quanto pela norte-americana. De forma geral, se enfatizam as negociações e a barganha brasileira em torno do alinhamento com os Estados Unidos, através da qual o Brasil obteve os créditos e equipamentos para a implantação da Companhia Siderúrgica Nacional e do amplo reequipamento de suas Forças Armadas. Do ponto de vista militar, grande ênfase é conferida à Força Expedicionária Brasileira e ao subseqüente

* Professor no Programa de Pós-Graduação em História da UPF. E-mail: svartman@upf.br 
alinhamento doutrinário e político aos EUA, que na década seguinte marcou as posições da cúpula militar brasileira. ${ }^{1}$

Um segmento importante da historiografia brasileira costuma assinalar que, passado o período no qual o Brasil conduziu sua política externa de forma pragmática, negociando com diferentes potências e barganhando seu alinhamento com os EUA, a posição internacional brasileira passou a pautar-se pelo "alinhamento automático" com aquele país. Tal alinhamento, especialmente no governo Dutra, estaria alicerçado na "ilusão" de que havia uma "aliança especial" entre ambos países, na qual o Brasil desempenharia uma posição chave na região e receberia o apoio norteamericano para manter a supremacia militar em face às demais republicas latino-americanas, conquistada durante a II Guerra. O resultado dessa política, conduzida num momento em que os EUA relegavam a América Latina a uma prioridade muito baixa em face do que se processava na Europa e na Ásia, não teria sido mais do que um "alinhamento sem recompensa". 2

Por outro lado, a historiografia norte-americana tende a enfatizar que após a II Guerra Mundial as relações militares entre os dois países tenderam a um esfriamento. Stanley Hilton sustenta que no decorrer da primeira década da Guerra Fria os Estados Unidos "perderam" o Brasil, o que teria acontecido pela incompreensão do Departamento de Estado quanto às demandas brasileiras por desenvolvimento de uma indústria bélica nacional e pela supremacia militar em relação à Argentina. O que Gerson Moura chamou de "desilusão", Hilton definira como uma "dramática erosão da confiança brasileira na relação especial" entre os dois países. Isso teria se manifestado na recusa brasileira em enviar tropas à guerra da Coréia, na adoção de medidas nacionalistas quanto ao petróleo e, bem mais tarde, no estabelecimento do acordo nuclear com a República Federal Alemã. ${ }^{3}$

1 SODRÉ, Nelson Werneck. História militar do Brasil. 3 ed. Rio de Janeiro: Civilização Brasileira, 1979; MOURA, Gerson. Autonomia na dependência: a política externa brasileira de 1935 a 1942. Rio de Janeiro: Nova Fronteira, 1980; BANDEIRA, Moniz. Presença dos Estados Unidos no Brasil. Dois séculos de história. Rio de Janeiro: Civilização Brasileira, 1973.

2 MOURA, Gerson. Sucessos e ilusões. Relações internacionais do Brasil durante e após a Segunda Guerra Mundial. Rio de Janeiro: FGV, 1991. p. 59s.; VISENTINI, Paulo. Relações internacionais e desenvolvimento. O nacionalismo e a política externa independente (1951-1964). Petrópolis: Vozes, 1995. p. 47.

3 HILTON, Stanley. The United States, Brazil and the Cold War, 1945-1960: end of a special relationship. The Journal of American History, vol. 68, n. 3, dez.1981, p. 600. 
Sonny Davis não fala em "perda", mas igualmente pontua que as estreitas relações militares entre Brasil e Estados Unidos se deterioraram após a II Guerra Mundial. O autor, contudo, matiza a afirmação, apontando que, quando havia "convergência de metas", as relações "refletiam a cooperação amistosa anterior" e, quando emergiam as divergências, o Brasil não seguia a liderança norteamericana. Isso teria levado o Brasil a "desenvolver confiança e habilidade para acabar com a prática tradicional de agir como subordinado de um poderoso protetor". Para Davis, esse processo de "amadurecimento" do Brasil como nação e particularmente dos militares brasileiros teria culminado com o fim do acordo militar entre os dois países em 1977.4

Face às posições apresentadas, neste artigo sustenta-se que as relações militares brasileiras com os Estados Unidos, mesmo em períodos de alinhamento em termos de política exterior, não eram de tutela. Argumenta-se que desde os anos 1930 os militares brasileiros tinham claro que a modernização de sua corporação e defesa nacional eficiente dependiam de uma aliança estratégica capaz de garantir armas, equipamentos e condições para o desenvolvimento de uma indústria bélica nacional - que, por sua vez, só seria possível com a industrialização do país como um todo. Este elemento informou as negociações com os EUA e com a Alemanha entre 1936 e 1942, de modo que sempre que o governo norte-americano apresentou dificuldades ou falta de interesse em atender a essas demandas o Brasil procurou outros meios. O pragmatismo sempre informou as relações militares entre Brasil e Estados Unidos, no período aqui abordado. Do ponto de vista militar, não se tratava, nem de longe, de uma relação entre iguais, mas tampouco foi de subordinação plena. Essa associação assimétrica visava a objetivos claros e bem definidos - era um meio para a obtenção de determinados fins.

Para dar conta dessa proposta, este artigo aborda os elementos pragmáticos que, em detalhe, pautavam as geralmente difíceis e não raro tensas negociações entre diferentes frações da oficialidade do Exército Brasileiro com seus homólogos norte-americanos. Antes de se deter nas negociações militares do Brasil com os Estados Unidos, é necessário pontuar alguns elementos que informaram essas negociações, mais especificamente o que se entende por

4 DAVIS, Sonny. Brazil-United States military relations in early post-World War II era. Revista Diálogos. Revista do Departamento de História da Universidade Estadual de Maringá. n. 6, 2004. 
pragmatismo e a visão da cúpula militar sobre a defesa nacional, a inserção internacional do Brasil naqueles anos, bem como os objetivos que, em função dessas percepções, eram formulados.

Por pragmatismo compreende-se uma forma realista de se proceder politicamente. Conforme Amado Cervo, trata-se de um dos componentes do "acumulado histórico" da política exterior brasileira que, junto com os princípios da não-intervenção e do juridicismo, define seus padrões de conduta. Conforme o autor, o pragmatismo

induz a adequação das percepções dos reais interesses nacionais aos desígnios externos, de forma a fazer prevalecer o resultado sobre o conceito, os ganhos concretos e materiais sobre os valores políticos e ideológicos, a oportunidade sobre o destino, a liberdade de ação sobre o empenho do compromisso, o universalismo sobre as camisas-de-força dos particularismos, a aceitação sobre a resistência aos fatos. ${ }^{5}$

É importante frisar que tal definição de pragmatismo não implica, necessariamente, em consenso entre os agentes envolvidos na formulação e execução da política exterior sobre os "reais interesses nacionais" e tampouco sobre a forma de se fazer prevalecer o "resultado sobre o conceito". O pragmatismo não isola o processo decisório da negociação, da persuasão ou do confronto pela definição das relações do Brasil com outros países, especialmente num contexto no qual o protagonismo militar na formulação de políticas (interna e externa) era bastante relevante. Da mesma forma, o padrão de conduta pragmático não é garantia de que os objetivos formulados sejam alcançados. As restrições do sistema internacional, a conjuntura e os objetivos dos demais países em questão, sobretudo as potências, têm um papel significativo na definição do espaço de manobra das políticas externa e de defesa brasileiras.

Desde o início da década e, de forma mais dramática, depois da guerra civil de 1932, havia um nítido consenso na cúpula militar brasileira em torno da debilidade da capacidade de defesa de suas forças armadas. A guerra do Chaco, a escalada militar na Europa e na Ásia, e o programa de rearmamento argentino - o então tradicional rival e inimigo potencial do Brasil - compunham um cenário cuja avaliação pelos militares brasileiros não era nada favorável ao seu país. O temor quanto à superioridade bélica argentina perpassou as negociações do Brasil com os Estados Unidos, e desencadeou um longo e sistemático período de monitoramen-

5 CERVO, Amado. Relações internacionais do Brasil. In: Id. O desafio internacional: a política exterior do Brasil. Brasília: Editora da UnB, 1994. p. 27. 
to político, econômico e militar do vizinho platino, levado a cabo tanto pelo Ministério da Guerra quanto pelo Itamaraty. ${ }^{6}$ Vários documentos produzidos pela cúpula militar associavam a precariedade das forças armadas brasileiras a uma situação de relegamento por parte das elites civis insensíveis às demandas por equipamento militar moderno, à excessiva politização dos quadros do Exército (conforme a célebre fórmula de Góes Monteiro, era a política no Exército e não a do Exército) e à inexistência de uma indústria de armas, suprimentos e equipamentos capaz abastecer minimante as Forças Armadas. ${ }^{7}$

Ainda que a obtenção de armas a curto prazo fosse prioridade e que as demandas militares pautassem boa parte da política comercial do Brasil, até a fase inicial da II Guerra Mundial ${ }^{8}$, a cúpula militar brasileira insistia também na necessidade de se ampliar a capacidade industrial como meio para o fortalecimento, a longo prazo, da sua corporação. No Relatório de 1936, o Chefe do Estado-Maior do Exército coloca a questão de forma a não amenizar a visão corrente no alto escalão daquela Força:

Não nos iludamos porque, à face do que observamos na vida política do Brasil, o Exército representa, e só ele, o sentimento profundo de coesão nacional. Trabalhando para a solução dos grandes problemas nacionais (siderurgia, combustíveis, etc.) o Estado-Maior do Exército procura concorrer para a nossa emancipação econômica, único meio de termos forças armadas eficientes. ${ }^{9}$

A questão do aparelhamento militar e da sua articulação com o desenvolvimento de uma indústria bélica, que por sua vez

6 SVARTMAN, Eduardo Munhoz. Diplomatas políticos e militares: as visões do Brasil sobre a Argentina durante o Estado Novo. Passo Fundo: UPF Editora, 1999.

7 Ver, por exemplo, Relatório apresentado ao Conselho Superior de Guerra pelo gen. Valdomiro Castilhos de Lima em 1935. AN AP51 cx. 5 doc. 1; ou MONTEIRO, Pedro Aurélio de Góes. A Revolução de 30 e a finalidade política do exército (esboço histórico). Rio de Janeiro: Andersen, 1934.

8 WIRTH, John. A política do desenvolvimento na era Vargas. Rio de Janeiro: FGV, 1973; HILTON, Stanley. A influência militar na política econômica brasileira, 1930-1945: uma reavaliação. In: Id. O Brasil e a crise Internacional: 1930-1945. Rio de Janeiro: Civilização Brasileira, 1977; e TRONCA, Ítalo. O Exército e a industrialização: entre as armas e Volta Redonda (1930-1942). In: FAUSTO, Bóris. História da civilização brasileira. v. 10. Rio de Janeiro: Bertrand, 1991.

9 Relatório dos trabalhos do EME, 1936 in: ESTADO-MAIOR DO EXÉRCITO. Documentos do Estado-Maior do Exército. Brasília: Estado-Maior do Exercito, 1996. p. 185. Neste período, o envolvimento do Estado-Maior do Exército com a siderurgia já mobilizava um de seus principais estabelecimentos de ensino, a Escola de EstadoMaior. Para essa questão, ver SVARTMAN, Eduardo Munhoz. Guardiões da Nação: Formação profissional, idéias e engajamento político dos generais de 1964. Tese de doutorado. Porto Alegre: UFRGS, 2006. p. 109. 
dependia a longo prazo da industrialização mais ampla do país, estava no núcleo da aliança estabelecida entre Getúlio Vargas e os militares por ocasião da implantação do Estado Novo. ${ }^{10}$ Sobretudo depois de 1937, Vargas assumiu o discurso militar, que fundia defesa nacional e industrialização. Isso se exemplifica quando, ao inaugurar a fábrica de pólvora de Piquete, SP, em julho de 1939, o "Chefe da Nação" afirmava ter chegado a hora de enfrentar o problema do aparelhamento do Exército:

O que era possível fazer dentro dos marcos do desenvolvimento industrial do país está realizado em boa parte. Esse empreendimento patriótico terá seu complemento definitivo quando começarmos a produzir ferro e aço para forjar os nossos canhões e a couraça dos nossos navios. E isso havemos de conseguir em breve. Já, de público, assumi o compromisso de montar no país a grande siderurgia, e aqui renovo, perante vós, como colaboradores decididos dessa obra de emancipação econômica e de segurança nacional. ${ }^{11}$

A cúpula militar tinha clareza que demandas dessa envergadura, que envolviam a pretensão de liderança regional e a reconquista da supremacia militar frente à Argentina, só poderiam ser atendidas com o apoio de uma potência industrial. ${ }^{12}$ A pendular aproximação comercial e militar com os Estados Unidos, com a Alemanha e com a Itália consistia no esboço das alternativas para viabilizar a redefinição da política externa brasileira, que desde então tem como vetor o desenvolvimento econômico. ${ }^{13}$

Desde 1934, militares dos exércitos do Brasil e dos Estados Unidos vinham empreendendo um processo de aproximação, ainda que modesto, com a implantação de uma missão militar que ministrou cursos para oficiais e sargentos brasileiros no recém criado Centro de Instrução de Artilharia de Costa, no Rio de Janeiro. ${ }^{14}$ Porém, diante da impossibilidade dos Estados Unidos fornecer os armamentos desejados pelo Brasil (a legislação norteameircana só começa a ser alterada em 1941), do traumático episódio no qual o arrendamento de alguns destroyers para a marinha

10 CARVAlHO, José Murilo de. Forças Armadas e Política, 1930-1945. In: A REVOLUÇÃO DE 30. Seminário Internacional CPDOC/FAV. Brasília: Editora da UnB, 1983. p. 148.

11 VARGAS, Getúlio. A nova política do Brasil. VI. Rio de Janeiro: José Olympio, 1939. p. 250.

12 MCCANN, Frank. Soldados da pátria: história do exército brasileiro. São Paulo: Companhia das Letras, p. 447.

13 CERVO, op. cit., p. 28.

14 Relatório do Ministro da Guerra. 1934. A cooperação militar, contudo, iniciara-se na Marinha com a contratação de uma missão naval em 1922. 
brasileira foi vetado pela Argentina e do desinteresse do setor privado norte-americano por investir em siderurgia no Brasil fez com que o "comércio compensado" com a Alemanha e a Itália se tornasse uma vantajosa alternativa, até a eclosão da guerra na Europa. A troca de armamentos pesados (artilharia de campanha, submarinos, etc.) por produtos primários da pauta brasileira de exportações tornouse também uma ferramenta de barganha nas negociações com os Estados Unidos em torno de uma adesão mais consistente em favor do bloco que Washington construía no continente.

Os objetivos que informavam as negociações dos militares brasileiros com os EUA podem ser sistematizados, assim, em $1^{\circ}$ ) obtenção de armamento moderno que a curto prazo garantisse a supremacia militar face à Argentina e municiasse o fortalecimento institucional que internamente se processava; $2^{\circ}$ ) obtenção de facilidades para o desenvolvimento de uma indústria nacional capaz de, a longo prazo, dar suporte às forças armadas. Esta pauta, formulada nos anos 1930, se prolongou na década seguinte mesmo após o final da II Guerra Mundial e a emergência da Guerra Fria. O cumprimento ou não desses objetivos era o que definia a conveniência ou não da cooperação militar com os EUA.

Do outro lado, os Estados Unidos vinham empreendendo uma ofensiva diplomática desde 1933 para unificar em torno de si os demais países do continente. $\mathrm{O}$ discurso mobilizado para consolidar um "sistema de poder" era o do pan-americanismo, viabilizado através de conferências inter-americanas, mecanismos de consulta mútua e da disposição de priorizar a negociação, a persuasão e, eventualmente, a pressão militar em detrimento das clássicas ocupações praticadas nas primeiras décadas do século XX na América Central e no Caribe. Com a eclosão das hostilidades na Europa, o Brasil passou a ter considerável importância estratégica para os EUA. As regiões nordeste e norte poderiam representar alvos numa eventual expansão do Eixo rumo ao ocidente partindo do norte da África, o que através de operações aeronavais colocaria em risco o canal do Panamá, passagem vital para a economia e as esquadras norte-americanas. No sentido inverso, bases franqueadas aos Estados Unidos, sobretudo no nordeste brasileiro, constituiriam, e de fato constituíram, escalas importantes para as contraofensivas dos Aliados. ${ }^{15}$

15 Para um detalhamento dos aspectos estratégicos e geopolíticos ver: ALVES, Vagner Camilo. O Brasil e a Segunda Guerra Mundial: história de um envolvimento forçado. São Paulo: Loyola, 2002. 
As negociações em torno de uma cooperação militar para além daquilo que os Estados Unidos propunham para América Latina nos termos do pan-americanismo começam a ser delineadas nas vésperas da Conferência de Lima, em 1938, por intermédio do Itamaraty. Em fins de maio do ano seguinte, ainda antes da eclosão da guerra na Europa, o chefe do Estado-Maior do Exército (EME) norte-americano visita o Rio de Janeiro e propõe abertamente às autoridades políticas e militares brasileiras a cooperação entre os dois países na defesa do continente e, em particular, do canal do Panamá. A cooperação, aceita pelas autoridades brasileiras, seria, contudo, "tanto maior quanto maior for a quantidade de material enviado pelos Estados Unidos". ${ }^{16}$

Este primeiro encontro, que se desdobrou na ida de Góes Monteiro, então chefe do EME brasileiro, aos EUA é particularmente importante porque os militares de ambos os países colocaram abertamente os objetivos, interesses e as condições envolvidos na cooperação que se pretendia alinhavar. Ao relatar sua estada em Washington a Vargas, Góes informa sobre as preocupações dos norte-americanos quanto à defesa do continente e a importância que então se conferia a Fernando de Noronha, e que, na possibilidade de uma cooperação com o Brasil, os Estados Unidos estariam "prontos a facilitar a aquisição do que necessitassem as suas Forças Armadas". Góes sabia que nada havia ainda de concreto, contudo recomendava estreitar as relações com os EUA, e para lá enviar oficiais qualificados na condição de adidos militares. Quanto à possibilidade de se obter armamento moderno, o general brasileiro, que nunca depositara entusiasmo no liberalismo ou na democracia e que era constantemente criticado, dentro e fora do Brasil, por suas inclinações germanófilas, explicitava o seu pragmatismo: "não teremos jamais outra oportunidade como a que se nos depara agora e perde-la seria absolutamente ridículo e impatriótico". Na mesma correspondência, Góes alerta Vargas de que, caso os Estados Unidos não obtenham do Brasil a cooperação esperada, eles iriam procurar a Argentina. ${ }^{17}$

De volta ao Brasil e após submeter a minuta ao ministro da Guerra, Eurico Gaspar Dutra e a Vargas, Góes envia uma longa

16 SVARTMAN, op. cit., p. 98; COUTINHO, Lorival. O general Góes depõe... Rio de Janeiro: Coelho Branco, 1955. p. 360. AHEx Arquivo Góes Monteiro caixa 9-A, pasta 5 , sub-pasta 2.

17 Carta de Góes Monteiro a Getúlio Vargas, 7/7/1939. In: SILVA, Hélio. 1939: véspera de guerra. Rio de Janeiro: Civilização Brasileira, 1972, p. 152. 
carta a seu homólogo norte-americano, George Marshall, na qual dá continuidade às "combinações e ajustes para a eventual cooperação (...) na hipótese de uma guerra". Informa também que o "centro de gravidade" das forças brasileiras está no sul do país, mas que se iniciará a preparação de bases aéreas no nordeste, e serão organizadas novas unidades para protege-las. Sinalizada a iniciativa brasileira, Góes explicita a contrapartida demandada: "conforme a ajuda material que os Estados Unidos puderem prestar ao Brasil, o programa de organização será então desenvolvido para a defesa completa do nordeste, Amazonas, Bahia, conjunto RioSantos, Santa Catarina e Rio Grande do Sul". O documento é ainda mais incisivo nos termos da barganha que então se desenhava:

Para esse fim o governo brasileiro necessita conhecer até que ponto e em que condições contará com o governo dos Estados Unidos para fornecimento do material de primeira urgência indispensável, cuja nota deixei em vosso poder, sendo que as particularidades de preços e pagamentos não poderão ser nunca menos vantajosas para o Brasil dos que as que até agora tem sido ajustadas e propostas pela Alemanha e outras nações. ${ }^{18}$

O clima ainda era de confiança e cordialidade, tanto que o número de oficias de ambos os países envolvidos no processo crescia. Porém começava a ficar evidente para a cúpula militar brasileira que as esperadas armas tardariam bastante. Na correspondência trocada por Marshall e Góes, nas semanas seguintes, que coincide com o início da fase européia da guerra, o militar norte-americano informa que a legislação de seu país impedia a venda de armas para o exterior nos termos desejados pelo Brasil, e Góes replica que seu país não dispõe de recursos para organizar sua segurança e ficaria, então, no "aguardo" para que os EUA fornecessem a sua ajuda indispensável. ${ }^{19}$

Blefes e pressões se sucedem num cenário internacional cada vez mais favorável às potências do Eixo. Em 11 de junho de 1940, o dia seguinte ao colapso da França, Vargas profere o famoso discurso a bordo do encouraçado Minas Gerais, cujas repercussões, de certa maneira, aceleraram as negociações em torno da siderurgia. As negociações militares também foram reavivadas, no dia seguinte ao discurso o embaixador norte-americano e o chefe da missão militar daquele país no Brasil, Lehman Miller, reuniam-se com o

18 Carta de Góes Monteiro a George Marshall, 8/8/1939. In: SILVA, op. cit., p. 156.

19 Carta de Góes Monteiro a George Marshall, 20/10/1939. AHEx Arquivo Góes Monteiro caixa 9-A, pasta 3, doc. 30. 
Chanceler brasileiro, Osvaldo Aranha, e, após, informaram o seu governo do risco de uma inflexão brasileira em favor da Alemanha. ${ }^{20}$ Em outubro Góes visita novamente os EUA, desta vez junto com os demais chefes de estado-maior da América Latina. Pessimista, informa a Vargas que pouco se avançou em termos de cooperação militar e que não se conseguia mais do que promessas do governo norte-americano. Ainda assim, procurou dar as cartas: ao entregar as instruções aprovadas pelo governo brasileiro para a cooperação militar a George Marshall e ao sub-secretário para América Latina, Sumer Welles, Góes frisa as vantagens fornecidas pelo Reich quanto ao fornecimento de material bélico ao Brasil. ${ }^{21}$

Nessa reunião, fora aprovada a criação de uma comissão mista de oficiais que se reunira no Brasil no ano seguinte para estudar planos e formas de cooperação na defesa do litoral nordeste brasileiro. A chefia dos membros norte-americanos dessa comissão coube ao mesmo Lehman Miller, que desde junho estava no Brasil e que, em 1938, fora o intérprete de Góes Monteiro em sua viagem aos Estados Unidos. Criada em 24 de junho de 1941, a comissão só se reuniu pela primeira vez no final do mês seguinte, e o ambiente já era de desconfianças, pois antes disso o próprio Miller expusera a Góes seus temores quanto às inclinações pró-Eixo de muitos oficiais brasileiros e a sua "estranheza" quanto à relativa indiferença por ele notada nos meios militares brasileiros quanto à ampliação da cooperação com os EUA. ${ }^{22}$

Ainda que os representantes de ambos exércitos tivessem pontos específicos para discutir sobre a cooperação na defesa do nordeste do Brasil, a primeira reunião foi pouco mais que um longo monólogo no qual Góes retoma os passos dados nas negociações até ali, reafirma a debilidade militar do Brasil, descreve a geografia das diferentes regiões brasileiras e encerra afirmando que a ajuda brasileira dependia apenas do recebimento do material necessário e que esta seria "a base de qualquer cooperação, pois o Brasil não delegará a nenhuma outra potência a função de defender seu próprio território". ${ }^{23}$

20 McCANN, Frank. Aliança Brasil-Estados Unidos, 1937-1945. Rio de Janeiro: Biblioteca do Exército, 1995. p. 168ss. Ver também VARGAS, Getúlio. Diário. Rio de Janeiro: FGV, 1995. p. 319s.

21 AHEx Arquivo Góes Monteiro caixa 9-A, pasta 3, doc. 29.

22 Documentos publicados em LEITE, Mauro R. Marechal Eurico Gaspar Dutra: o dever da verdade. Rio de Janeiro: Nova Fronteira, 1983. p. 431 e 425ss.

23 Ata de instalação da Comissão Mista de Oficiais Brasileiros e Americanos. AHEx Arquivo Góes Monteiro caixa 9-A, pasta 5, sub-pasta 5. A comissão tinha a seguinte composição: Góes, que presidia os trabalhos, os generais Mário Ary Pires e Lehman Miller, coronéis Canrobert Pereira da Costa, Luiz Procópio de Souza Pinto, E. D. Sibert, Mc Cunnuf e Leonard, tenentes-coronéis Hale e Bina Machado, majores Hertford e José Coelho dos Reis. 
Nas reuniões seguintes, embora fossem entregues aos norteamericanos documentos e mapas do litoral nordestino e se combinasse uma visita àquela região, prosseguiam os monólogos de Góes. Porém, quando foi feita a leitura da primeira ata, na qual Góes Monteiro afirma que o que o Brasil mais precisa é de material, o que vem sendo solicitado sem sucesso junto aos EUA, Miller interpela e é retrucado rispidamente por Góes, para quem a ata registrava apenas o que se passara na reunião. Em resposta, Miller reitera que fora aberto um crédito de US\$100 milhões, do qual o Brasil só pagaria $35 \%$ do valor dos artigos encomendados, e esse crédito poderia ainda ser aumentado. Góes responde que, apesar de saber das dificuldades dos EUA de suprir a Inglaterra e a si, tem sido "pouco satisfatórias as condições de auxílio material dos Estados Unidos para o Brasil" ${ }^{24}$ Neste clima é encerrada a terceira reunião. $\mathrm{O}$ único avanço registrado nas reuniões que se seguiram foi uma viagem de reconhecimento do nordeste feita pelos oficiais norte-americanos e a confecção de planos genéricos de defesa e recomendações de construção de bases.

Além das armas, havia outra questão de difícil negociação e que contribuiu para acirrar os ânimos. Diante da debilidade militar do Brasil, da lentidão das negociações e, no entender do Departamento da Guerra, da limitada mobilização militar brasileira, os norte-americanos pretendiam deslocar tropas suas para realizar a defesa da região. Assim, sucessivos planos de envios de tropas, em torno de 60 mil homens, com e sem autorização brasileira foram elaborados e as reiteradas demandas nesse sentido acentuaram tanto as precauções dos militares brasileiros quanto as tensões entre os membros do governo Vargas. ${ }^{25}$

Ainda em agosto de 1941 os militares brasileiros tiveram acesso ao relatório de Lehman Miller sobre os projetos de defesa do hemisfério, no qual informa a seus superiores que as "autoridades do Exército Brasileiro parecem sentir verdadeiro horror da presença de tropas americanas em território brasileiro", e que se sente pouco otimista quanto aos trabalhos da comissão de oficiais dos dois países, porque seus trabalhos são presididos pelo general Góes Monteiro, "que é muito oportunista para que nele se possa confiar. Ainda que não mantenha atitude inamistosa com os Estados

24 Ata da terceira Sessão da Comissão Mista Brasileiro-Americana. AHEx Arquivo Góes Monteiro caixa 9-A, pasta 5, sub-pasta 5.

25 McCANN, 1995, p. 186 e 200. 
Unidos, não simpatiza com a Inglaterra nem com a forma de governo democrática". Miller faz a mesma apreciação de Dutra, e reitera que o Brasil aceitaria a cooperação militar, desde que não fossem enviadas tropas e sim equipamento militar. ${ }^{26}$ Se as negociações militares mostravam-se difíceis e tensas, uma via encontrada para agilizar o processo de cooperação entre os dois países se operacionalizou através das construções de aeroportos no nordeste pela Panair, subsidiária Pan-American, no Brasil. Ainda que o caráter militar da empreitada fosse óbvio, tanto a empresa quanto a autoridade brasileira que regulava e supervisionava a aviação eram civis, pois o recém-criado Ministério da Aeronáutica ficara a cargo de um civil próximo a Osvaldo Aranha, Salgado Filho, numa clara manobra de Vargas para dividir e reacomodar as forças que davam sustentação ao regime. ${ }^{27}$

Em setembro, após o retorno dos oficiais norte-americanos de sua viagem de reconhecimento do nordeste brasileiro, Dutra escreve a Vargas considerando "injustificável" e "inconcebível" a presença de tropas dos EUA no Brasil, o que, segundo o ministro, "anularia nossa soberania na região [convertendo-a] em mero território de ocupação estrangeira". Em seu diário, Vargas anota: "os americanos querem nos arrastar à guerra na Europa sob pretexto de defesa da América". As tensões não param de crescer, em 24 de outubro Vargas alude à intenção de Aranha se demitir do Itamaraty. ${ }^{28}$

Em 27 de outubro Miller, que acabara de retornar dos EUA, resolve pressionar diretamente o ministro da guerra brasileiro, informando das dificuldades de fornecimento de material bélico, das desconfianças quanto à atitude brasileira e, num tom de ameaça, do "firme propósito" de seu país enviar tropas para guarnecer o nordeste brasileiro. Dutra informa a Vargas que, por sua vez, teria dito que "deveríamos resistir o quanto pudéssemos", e que as declarações do militar norte-americano teriam ligação com a atitude de Osvaldo Aranha, que viria insistindo em exonerar-se. ${ }^{29}$ No dia 29, Lehman Miller repete a investida com Góes Monteiro, dando a entender que no Departamento da Guerra prevalece a opinião da ocupação do nordeste sem prévia autorização brasileira em decorrência das informações de que grande parte do exército brasileiro nutre forte simpatia pelos feitos das armas germânicas,

26 LEITE, op. cit., p. 446.

27 McCANN, 1995, p. 184.

28 LEITE, op. cit., p. 460. VARGAS, 1995, p. 424 e 430.

29 LEITE, op. cit., p. 466. 
especialmente o Ministro da Guerra e o Chefe do EME. Góes teria respondido que o Brasil vinha cumprindo lealmente seus compromissos, tendo inclusive autorizado a construção de bases em seu território e disponibilizado informações sigilosas aos EUA, teria ainda argüido que "confiança não se poderia impor e, no caso em apreço, para se obter os efeitos desejados, ela deveria ser recíproca". Por fim, de forma um tanto dramática, Miller informa sua intenção de demitir-se do cargo, após relatar a conversa a Washington, Góes teria apenas respondido que não interferiria numa questão de foro íntimo e, ironicamente, agradece por sua colaboração no estreitamento das relações entre ambos os exércitos. ${ }^{30}$ Depois de ser informado, Vargas anota em seu diário que o caso assumiu "um aspecto grave, porque não é uma colaboração, é uma violência". Vargas sonda o embaixador norte-americano, que nega ser intenção do governo desembarcar tropas no Brasil, o que pode ter revelado aos brasileiros os dissensos entre o Departamento de Estado e o da Guerra. ${ }^{31}$ A crise, contudo, prolongou-se, e em novembro é Dutra quem solicita a demissão do cargo, Vargas não aceita, e em dezembro ocorre o incidente no qual fuzileiros norte-americanos são impedidos de desembarcar pelas autoridades militares brasileiras. O relatório do Ministério da Guerra do ano de 1941 não usou meias palavras para descrever o quão longe se estava, na visão da cúpula militar, de uma aliança especial ou de uma adesão irreversível aos Estados Unidos:

No decorrer de 1941 [surgiram] muitos impasses e atritos com os representantes do "War Departament", sobretudo devido às questões suscitadas sobre a ocupação de bases no território nacional e à falta de cumprimento das promessas de fornecimento de material bélico por parte dos Estados Unidos.

Os incidentes se repetiram da maneira a mais desagradável (...) e a conduta dos representantes do "Staff dos USA" nem sempre foi cordial e hábil, demonstrando desconfianças, evasivas, exigências intoleráveis, intromissões indébitas com relação ao pessoal do Exército e até falsidades - fruto em parte da desorientação e desenvoltura da "guerra de nervos" atirada e atiçada em certos círculos de propaganda interna contra o Alto Comando do Exército.

Depois da clara alusão à atuação do ministro das relações exteriores, que expõe a clivagem na cúpula governamental, o relatório prossegue em tom ameaçador:

30 CPDOC/FGV GV 1941.10.30/3.

31 VARGAS, 1995, p. 431s. 
Essa incompreensão dominante atinge as raias da inconsciência e no futuro poderá produzir terríveis conseqüências. (...). O EME muitas vezes foi posto em cheque e é difícil prever em caso de crise aguda até que ponto os resíduos dessas questões e seus efeitos nocivos irão influir nos destinos da Nação. (...). Quanto à capacidade de preparação militar (...) o pouco que se tem adiantado não representa uma garantia de tranqüilidade para a defesa no país, (...) achando-se o essencial na dependência quase exclusiva da boa vontade dos Estados Unidos. ${ }^{32}$

Somente com a entrada oficial dos Estados Unidos na guerra (conseqüência do ataque japonês à base de Perl Harbor), com a remoção de Lehman Miller e com novas promessas de Roosevelt de enviar os armamentos solicitados pelo Brasil, é que as tensões foram parcialmente dissipadas. A nova e definitiva rodada de negociações se deu durante a III Reunião Consultiva de Chanceleres, realizada em janeiro de 1942, no Rio de Janeiro, ao fim da qual o Brasil rompera relações diplomáticas com o Eixo. O difícil processo de tomada de decisão pela ruptura, no qual o ministro da guerra foi voto vencido, a declaração de guerra em agosto e as subseqüentes negociações em torno da FEB seguiram um padrão não tão conflituoso quanto o incidente aqui detalhado, mas pautado pelas mesmas orientações pragmáticas.

Nesse sentido, é importante assinalar que, mesmo no governo Dutra, freqüentemente apontado como modelo de "alinhamento automático" à política externa norte-americana, a pauta do desenvolvimento de uma indústria bélica nacional se fez presente nas pouco frutíferas negociações militares com os Estados Unidos. A partir de 1945, a cooperação militar dos EUA com a América Latina se dera no marco da guerra fria, sendo "institucionalizada" em 1947, com o TIAR, e em 1948, com a OEA, de modo que, até a revolução cubana, a mesma se deu num contexto de baixa prioridade para os EUA. 33

O estreitamento da margem de manobra internacional, a debilidade econômica e as frustrações quanto à pretensão brasileira de desempenhar um papel de maior relevância no cenário regional - associado aos Estados Unidos - não impediu que, por meio de

32 Relatório dos trabalhos do EME, 1941. In: ESTADO-MAIOR DO EXÉRCITO. Documentos do Estado-Maior do Exército. Brasília: Estado-Maior do Exercito, 1996. p. 253ss.

33 MOURA, 1991; e MARTINS FILHO, João Roberto. As políticas militares dos EUA para a América Latina (1947-1989). Teoria e Pesquisa. São Carlos, n. 46, jan. 2005. p. 101-135. 
compras, as Forças Armadas procurassem incentivar a fabricação de artigos militares pela indústria privada nacional. Em sua mensagem presidencial de 1949 ao Congresso brasileiro, o presidente Dutra referencia os conflitos da Guerra Fria e ampara-se no modelo de guerra total para enfatizar a necessidade de se preparar reservas na indústria de guerra e demais setores ligados à defesa externa. Frisa ainda que as restrições orçamentárias não diminuíram a "preocupação do (...) governo desenvolver a indústria bélica do país, que, além do mais, incentivará a indústria civil nacional". ${ }^{34}$

É bem sabido que no pós-II Guerra Mundial a política externa brasileira, como um todo, operou de forma alinhada com a dos Estados Unidos, tendo havido uma forte convergência entre o anticomunismo dos militares brasileiros - que, por sua vez, estava na raiz dos golpes de criação e de derrubada do Estado Novo - e o anticomunismo que então informava os programas de assistência militar dos EUA para a América Latina. ${ }^{35}$ Entretanto, havia um sério entrave à assimilação plena das doutrinas militares norteamericanas no meio brasileiro. Conforme o relatório de 1945 do EME, o Centro de Aperfeiçoamento e Especialização do Realengo já incorporaria a "doutrina americana" na instrução ali praticada. Porém, o mesmo relatório ponderava também que o emprego generalizado do equipamento norte-americano e a conseqüente adoção da organização e doutrina militar daquele país se mostravam um tanto problemáticos, pois já se identificavam as sérias limitações quanto à motorizarão da força brasileira, carente tanto de viaturas quanto de estradas. Já o relatório de 1948 informava ao ministro da Guerra que naquele contexto de transição e reestruturação, que procurava assimilar as experiências colhidas durante a II Guerra Mundial e moldar-se à organização e aos equipamentos norteamericanos, um sério "reajustamento" teve de ser feito em virtude da súbita "privação de meios" a que fora submetido o Exército. ${ }^{36}$

Pelo que se pode apreender da documentação, antes mesmo do fim da década de 1940 já estava claro para os militares brasileiros

34 Mensagem do Presidente Eurico Gaspar Dutra ao Congresso Nacional, 1947, p. 106; 1949 , p. 95ss.

35 HAINES, Gerald. The Americanization of Brazil: a study of US cold war diplomacy in the Third World (1945-1955). Wilmington: Scholarly Resources, 1989. p. 42; e MOTTA, Rodrigo Sá. O anticomunismo militar. In: MARTINS FILHO, João Roberto (org.). O golpe de 1964 e o regime militar: novas perspectivas. São Carlos: EdUFSCar, 2006.

36 Relatório dos trabalhos do EME, 1945 e 1948. In: ESTADO-MAIOR DO EXÉRCITO. Documentos do Estado-Maior do Exército. Brasília: Estado-Maior do Exercito, 1996. p. 287 e 296. 
que os créditos políticos acumulados durante a II Guerra Mundial não seriam revalidados. O episódio da transferência de dois cruzadores norte-americanos para a Marinha Brasileira, ao mesmo tempo e em igualdade de condições para as marinhas chilena e Argentina, puseram fim a qualquer expectativa de que o Brasil possuísse algum trunfo especial. Restava, então, voltar-se novamente para outros fornecedores, especialmente europeus ${ }^{37}$ e, na medida do possível, dar continuidade ao desenvolvimento de uma indústria bélica nacional que viesse a garantir um certo grau de autonomia ao suprimento das Forças Armadas. Menos que uma desilusão ou que uma perda de confiança, essa inflexão nada mais foi do que a continuidade de um mesmo padrão pragmático de relações militares com os Estados Unidos.

37 ALVES, Vagner Camilo. Ilusão desfeita: a "aliança especial" Brasil-Estados Unidos e o poder naval brasileiro durante e após a Segunda Guerra Mundial. Revista Brasileira de Política Internacional. 48, (1), 2005, p. 171. 